\title{
Three-dimensional Static Ultrasound and 3D Power Doppler in Gynecologic Pelvic Tumors
}

\author{
Juan Luis Alcázar
}

\begin{abstract}
Gynecological tumors are a frequent clinical problem. Accurate diagnosis is essential for an adequate clinical management. Currently, 2D ultrasound is considered as a first line imaging technique for diagnosis and for discriminating benign from malignant lesions. However, some limitations of this technique exist. Three-dimensional is a relatively new technique that allows some unique ways for assessing gynecological tumors by ultrasound. In this article, I shall review current evidence about the use of three-dimensional ultrasound for assessing gynecological tumors.
\end{abstract}

Keywords: Three-dimensional ultrasound, Gynecological, Cancer.

How to cite this article: Alcázar J L. Three-dimensional S tatic Ultrasound and 3D Power Doppler in Gynecologic Pelvic Tumors. Donald School J Ultrasound Obstet Gynecol 2013; 7(2):187-199.

\section{Source of support $\mathrm{Nil}$}

Conflict of interest: None declared

\section{INTRODUCTION}

Pelvis tumors from gynecologic origin are common disorders in clinical practice. Ultrasound has been used largely for the differential diagnosis of pelvic tumors, such as endometrial, myometrial and adnexal pathologies.

In the case of endometrial cancer, the measurement of endometrial thickness has been proved to be an effective method to exclude malignancy. ${ }^{1}$ However, a thickened endometrium is a nonspecific finding. The use of pulsed Doppler remains controversial ${ }^{2,3}$ and for this reason some authors have advocated the use of color mapping for differentiating endometrial cancer from other benign conditions. ${ }^{4}$ However, this approach is only reproducible in experienced hands. ${ }^{5}$

$U$ terine myomas are a very common benign disease. The diagnosis use to be easy by ultrasound ${ }^{6}$ and there is evidence that uterine blood flow is increased in the presence of fibroids. ${ }^{7}$ Some authors have stated that the use of color Doppler may discriminate benign fibroids from uterine sarcomas. ${ }^{8}$ However, other authors have challenged this concept. $^{9,10}$

Cervical cancer has been largely obviated from the assessment by ultrasound. However, recently the assessment of tumor vascularization in cancer of the uterine cervix has gained attention from researches, because some studies have shown that it may be possible to predict therapeutic response to neoadjuvant chemotherapy or chemoradiation. ${ }^{11,12}$

A dnexal masses are probably one of the most frequent problems in gynecology. Patients with questionable adnexal tumors should be referred to a gynecologic oncologist specialist ${ }^{13}$ whereas benign tumors should be treated by laparoscopic surgery by general gynecologist ${ }^{14}$ or even managed expectantly. ${ }^{15} \mathrm{M}$ orphological ultrasound assessment of adnexal masses can be considered as the primary imaging modality to be used because of its high sensitivity. However, false-positive rate remains high. ${ }^{16} \mathrm{~T}$ he role of pulsed Doppler is still controversial. ${ }^{17}$

Some authors have proposed a simpler approach by just looking tumor blood flow mapping with encouraging results. ${ }^{18}$

In the last years, three-dimensional ultrasound (3D USG) has become available in clinical practice, opening a formidable research area. ${ }^{19}$

The objective of the present chapter is to review current evidence of the use of 3D USG and three-dimensional power Doppler ultrasound (3D PD-USG) in the evaluation of pelvic gynecologic tumors.

\section{ENDOMETRIAL CANCER}

Few studies have evaluated the role of 3D ultrasound in the diagnosis and assessment of endometrial cancer.

Three-dimensional ul trasound allows the assessment of endometrial volume (Figs 1 and 2). In our experience, this measurement is highly reproducible. ${ }^{20}$ The intraobserver intraclass correlation coefficient (ICC) is 0.97 and the interobserver ICC is 0.70 .

Gruboeck compared the diagnostic performance of endometrial thickness and endometrial volume in a series of 103 women with postmenopausal bleeding. ${ }^{21}$ They found that both mean endometrial thickness (29.5 vs $15.6 \mathrm{~mm}$ ) and endometrial volume (39.0 vs $5.5 \mathrm{ml}$ ) were significantly higher in women with endometrial cancer as compared with those with benign conditions. Using a cutoff of $15 \mathrm{~mm}$ for endometrial thickness and $13 \mathrm{ml}$ for endometrial volume, this parameter was more sensitive (100 vs $83 \%$ ) and had a higher positive predictive value (91.7 vs $54.5 \%$ ).

Kurjak et al ${ }^{22}$ evaluating a series of 41 women with suspected endometrial pathology obtained similar results. 


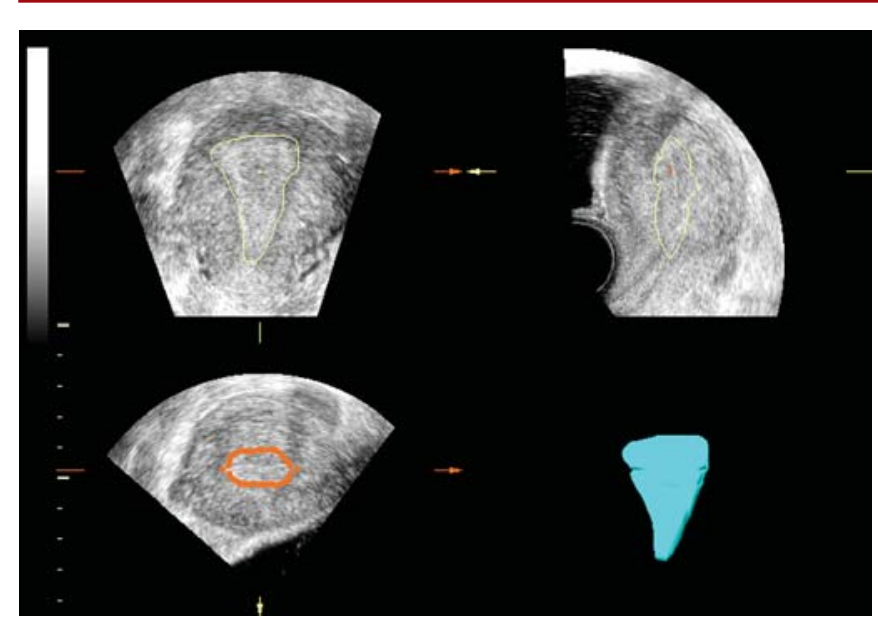

Fig. 1: Endometrial volume calculation by using the VOCAL rotational method

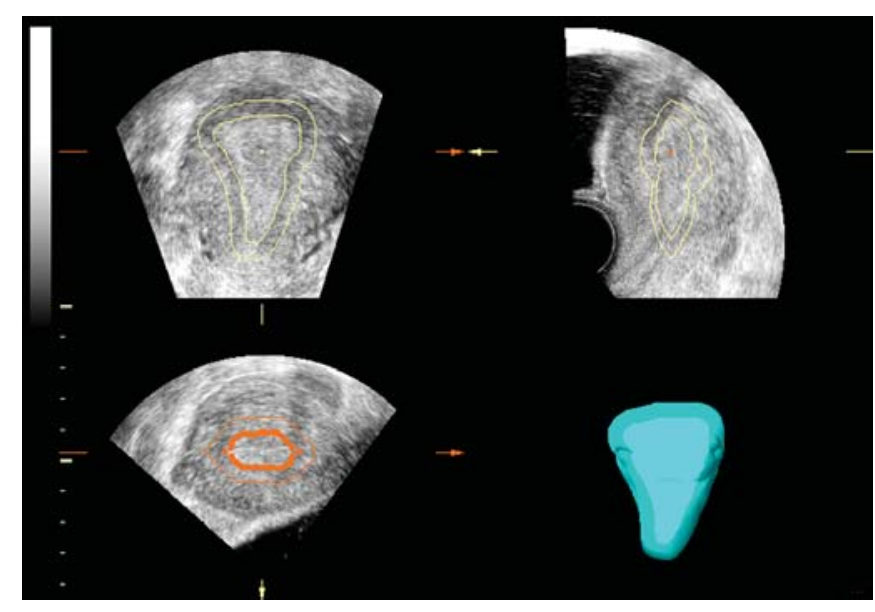

Fig. 2: Subendometrial area volume calculation by using the VOCAL rotational method

They reported that endometrial volume as well as endometrial thickness was significantly higher in women with endometrial cancer as compared with those patients with benign conditions such as polyps, endometrial hyperplasia or cystic atrophy.

M ore than one decade later, $M$ ansour et al reached the same conclusions than Gruboeck et al comparing endometrial volume and thickness in a series of 170 women with postmenopausal bleeding. ${ }^{23}$ However, these authors reported that the best cutoff for endometrial volume was $1.35 \mathrm{ml}$ with a sensitivity of $100 \%$ and a false-positive rate of $29 \%$, much higher than that reported by Gruboeck. A n explanation for that is that $M$ ansour's study included patients with 'endometrial atypia' in the group of endometrial cancer.

However, Y aman et al found that endometrial volume was more specific than endometrial thickness in a series of 213 women, 42 with endometrial cancer. ${ }^{24}$ W ith a cutoff of $2.7 \mathrm{ml}$, sensitivity was $100 \%$ and specificity was $69 \%$. O deh et $\mathrm{al}^{25}$ and $\mathrm{M}$ erce et $\mathrm{al}^{26}$ have reported similar findings.

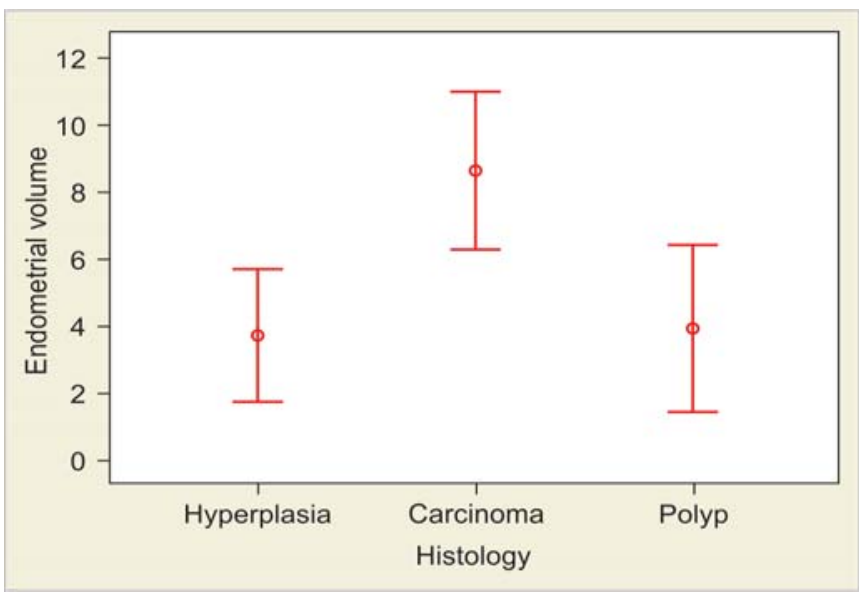

Fig. 3: Mean endometrial volume with $95 \%$ Cls in endometrial cancer, hyperplasia and polyps

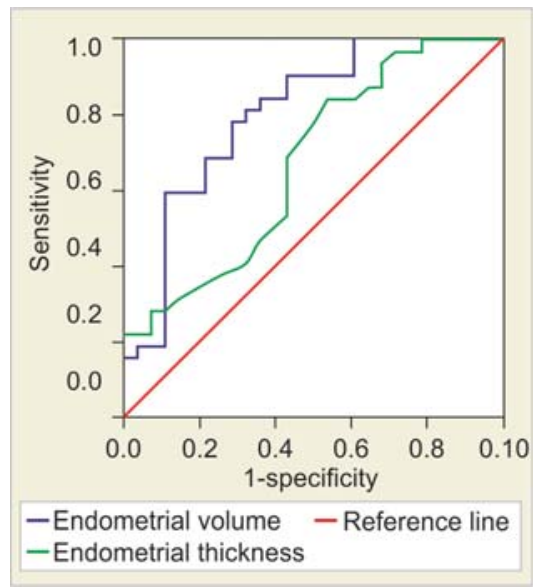

Fig. 4: Receiver-operating characteristic (ROC) curves for endometrial thickness and endometrial volume for detecting endometrial cancer in women with postmenopausal bleeding

Opolskiene et al did not find differences between endometrial volume and thickness in the terms of sensitivity and specificity for diagnosing endometrial cancer. ${ }^{27}$

In our experience, ${ }^{28}$ in a series of women with postmenopausal bleeding and thickened endometrium ( $>5 \mathrm{~mm}$ ) we also found that endometrial volume was significantly higher in endometrial cancer as compared with polyps or hyperplasia (Fig. 3). In agreement with previous authors endometrial volume is more specific than endometrial thickness (Fig. 4).

These studies are summarized in Table 1.

The use of 3D ultrasound has been also found to be effective to assess myometrial invasion in endometrial cancer by analyzing the myometrial-endometrial interface and to estimate the maximum penetration of the tumor within the myometrium ${ }^{29,30}$ (Figs 5 and 6). Our group described and analyzed the diagnostic performance of a new method for assessing myometrial infiltration preoperatively based on 3D ultrasound. ${ }^{31}$ This new approach was based on a 3D 
Three-dimensional Static Ultrasound and 3D Power Doppler in Gynecologic Pelvic Tumors

\begin{tabular}{lcccccc}
\hline \multicolumn{7}{c}{ Table 1: Endometrial volume compared with endometrial thickness for diagnosing endometrial cancer in } \\
women with postmenopausal bleeding
\end{tabular}

EC: endometrial cancer; ET: endometrial thickness; EV: endometrial volume; *Endometrial hyperplasia and cancer included in the same 'pathologic' group; ${ }^{\dagger}$ Retrospective study assessing only women with endometrial hyperplasia and cancer; ${ }^{\ddagger}$ P rospective study including only women with thickened endometrium

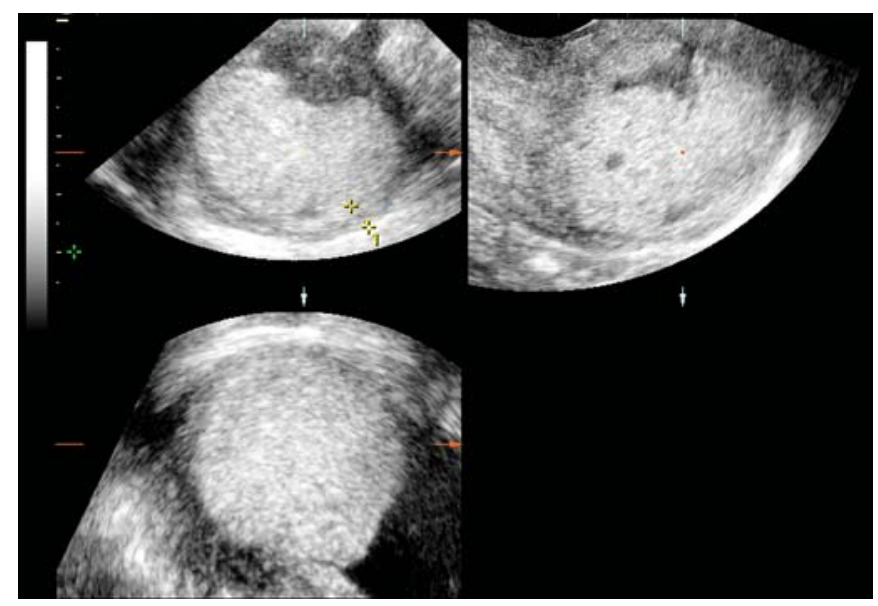

Fig. 5: Estimation of myometrial invasion in endometrial cancer by using 3D multiplanar navigation. In this case, infiltration is considered as deep

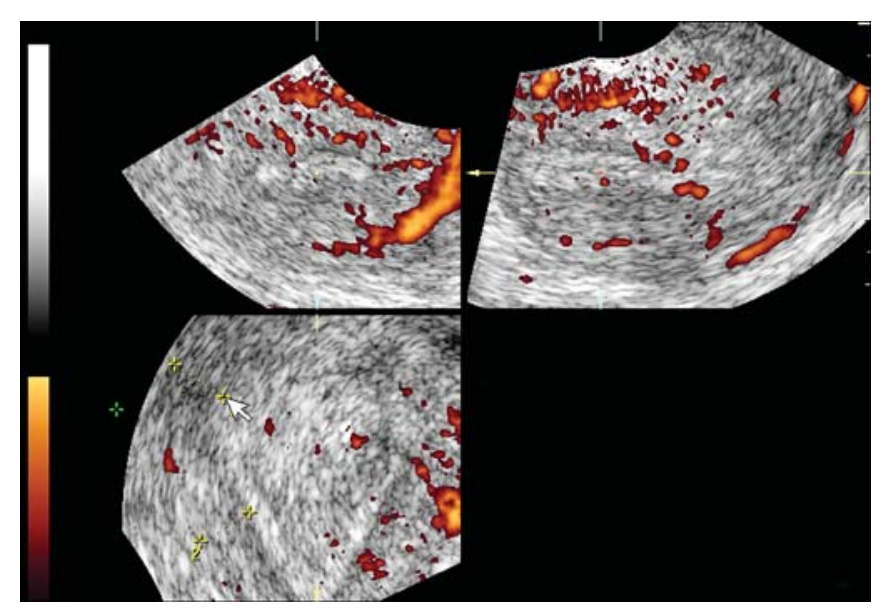

Fig. 6: Estimation of myometrial invasion in endometrial cancer by using 3D multiplanar navigation. In this case, infiltration is considered as superficial

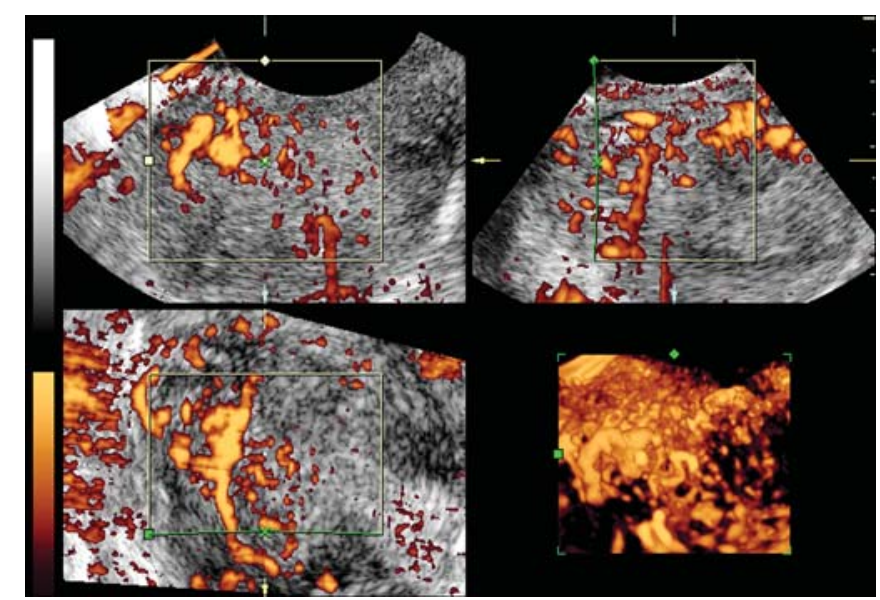

Fig. 7: Three-dimensional power Doppler depiction of vascular architecture in a case of endometrial cancer. Chaotic pattern is clearly seen

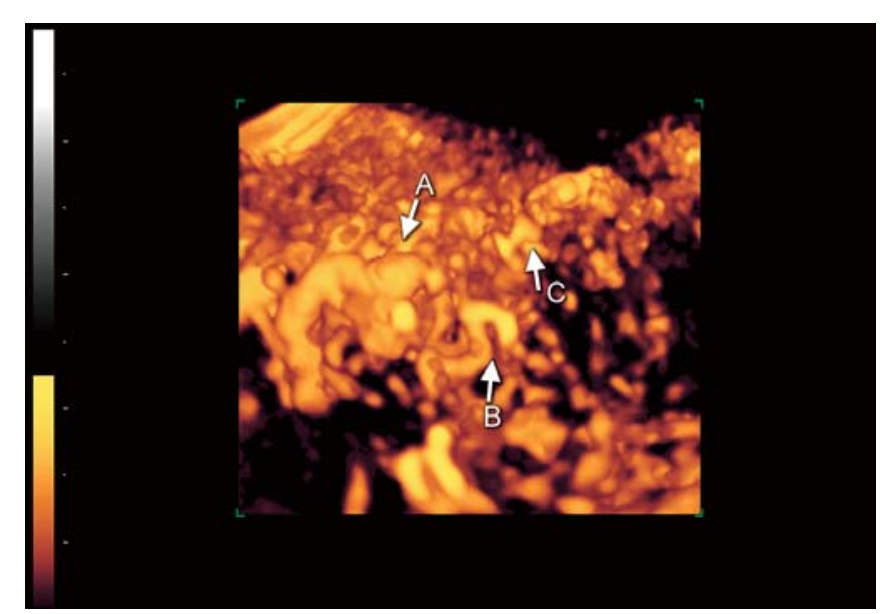

Fig. 8: Same as Figure 7. Different vessel caliber (A), abnormal branching $(\mathrm{B})$ and microaneurysms $(\mathrm{C})$ are seen 
virtual navigation through the uterus for detecting the deepest point of myometrial infiltration in a series of 96 women with endometrial cancer. Sixty-nine women had $<50 \%$ myometrial infiltration on histologic analysis and 27 had $>50 \%$ myometrial infiltration. The most interesting finding from this study was the negative predictive value reported (100\%) using this approach. The false-positive rate reported was $39 \%$. The reproducibility of the method was good.

A nother possibility for 3D ultrasound is the assessment of tumor vascularity by 3D PD. ${ }^{32}$ This technique allows the depiction of vascular netw ork in endometrial lesions as well as the estimation of three vascular indexes (VI, FI and VFI) by the VOCAL ${ }^{\mathrm{TM}}$ rotational method. Vascular network in malignant tumor used to be irregular with chaotic branching, changes in vessels caliber, pseudoaneurysms (Figs 7 and 8). On the other hand, these features used to be absent in benign conditions such as polyp (Fig. 9) or hyperplasia (Fig. 10).

$\mathrm{K}$ upesic et al reported that assessing the vascular network by 3D PD they were able to determine correctly the depth of myometrial invasion in 21 out of 22 women with endometrial cancer. ${ }^{33}$ They assessed the presence of chaotic vessels in the endometrial-myometrial interface.

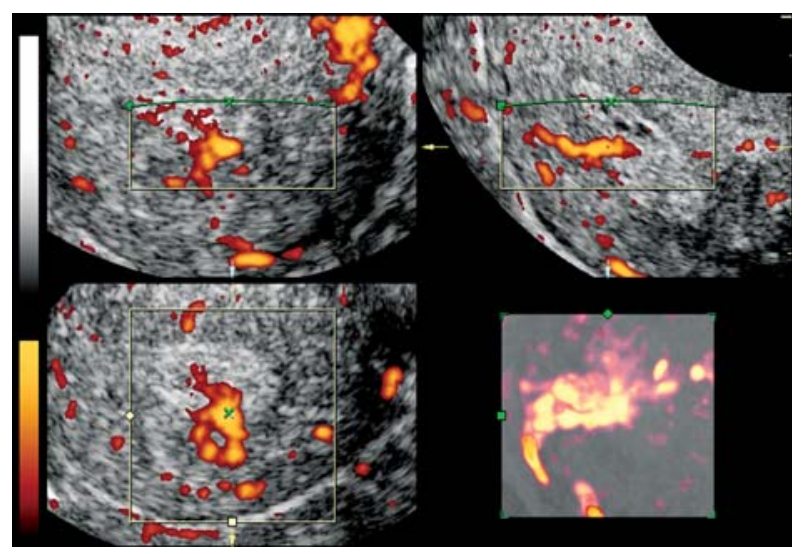

Fig. 9: Vascular pattern for an endometrial polyp. A single predominant vessel is seen within the lesion

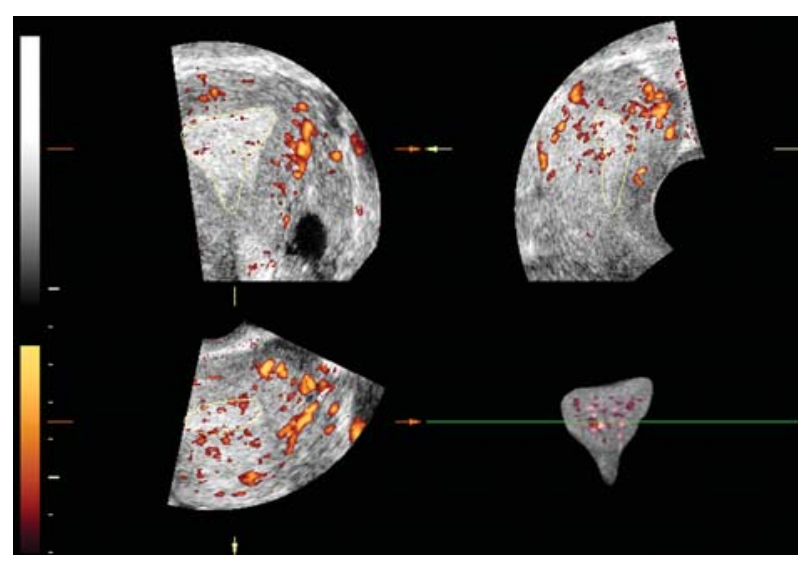

Fig. 10: Vascular pattern for endometrial hyperplasia. Scattered vessels can be seen within the endometrium

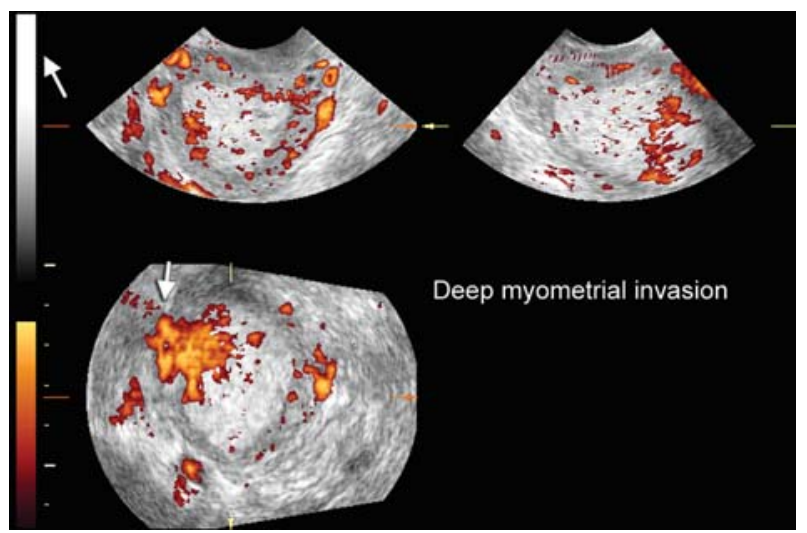

Fig. 11: Assessment of myometrial invasion by three-dimensional power Doppler. In this case, deep myometrial infiltration was considered at the level of the right uterine cornu
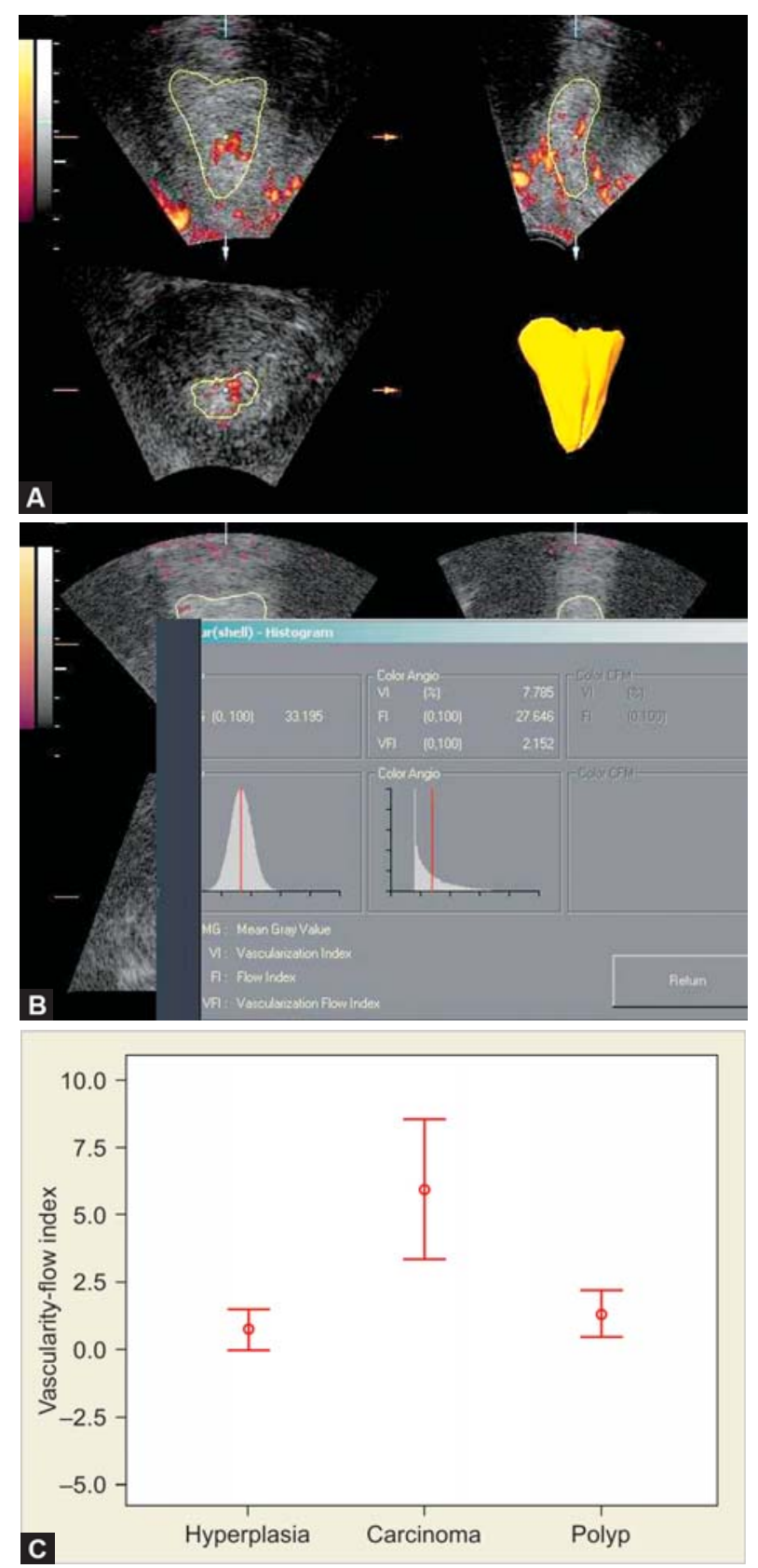

Figs 12A to C: Three-dimensional power Doppler volume and indices calculated in a case of endometrial cancer 
Depending on whether more than half or less than half of the myometrium was involved by these chaotic vessel, patients were considered as having deep or superficial myometrial invasion (Fig. 11).

The use of vascular indexes (Figs 12A to $\mathrm{C}$ ) has not been extensively assessed. O deh et al reported that all three 3D PD indexes were significantly higher in women with endometrial cancer as compared with those with benign pathology. ${ }^{25}$ However, they did not compare with conventional 2D PD and the specificity reported was low. Mercé et al found that 3D PD indexes were significantly higher in women with endometrial cancer as compared with those with endometrial hyperplasia. ${ }^{26}$ A lcázar et al also found that 3D PD indexes were significantly higher in women with endometrial cancer as compared with those with benign pathology, ${ }^{28}$ but this study included only women with endometrial thickness above $5 \mathrm{~mm}$ and did not compare $3 \mathrm{D}$ results with conventional $2 \mathrm{D}$ color Doppler. Opolskiene et al reported data in a series of women with postmenopausal bleeding and endometrial thickness $\geq 4.5 \mathrm{~mm} .{ }^{27}$ They concluded that although 3D PD indexes were significantly higher in women with endometrial cancer as compared with those with benign pathology, this technique adds little information to endometrial thickness or volume. Lieng et al analyzed a small series of women with endometrial polyps ( $n=17)$ and endometrial cancer $(n=17)$ comparing 3D PD indexes within the lesions before and after contrastenhanced examination. ${ }^{29}$ They did not find differences between groups in 3D PD indexes.

Galvan et al assessed the correlation between intratumoral 3D PD indexes and several histological tumor characteristics in a series of 99 women with endometrial cancer. ${ }^{34}$ In their analysis endometrial volume and vascularization index were independently associated with myometrial infiltration and tumor stage, vascularization index was independently associated with tumor grade and endometrial volume correlated with lymph node metastases.

In conclusion, endometrial volume seems to be a better predictor for endometrial cancer than endometrial thickness in women with postmenopausal bleeding. Threedimensional power Doppler assessment of endometrial vascularity is reproducible and seems to be useful for differentiating endometrial cancer than benign endometrial conditions. Its performance seems to be better than endometrial volume. This technique al so seems to be useful to predict some histological features of endometrial cancers, especially myometrial invasion.

\section{UTERINE LEIOMYOMAS AND SARCOMAS}

Uterine fibroids are the most common pelvic tumors of women in reproductive age. The sonographic appearance

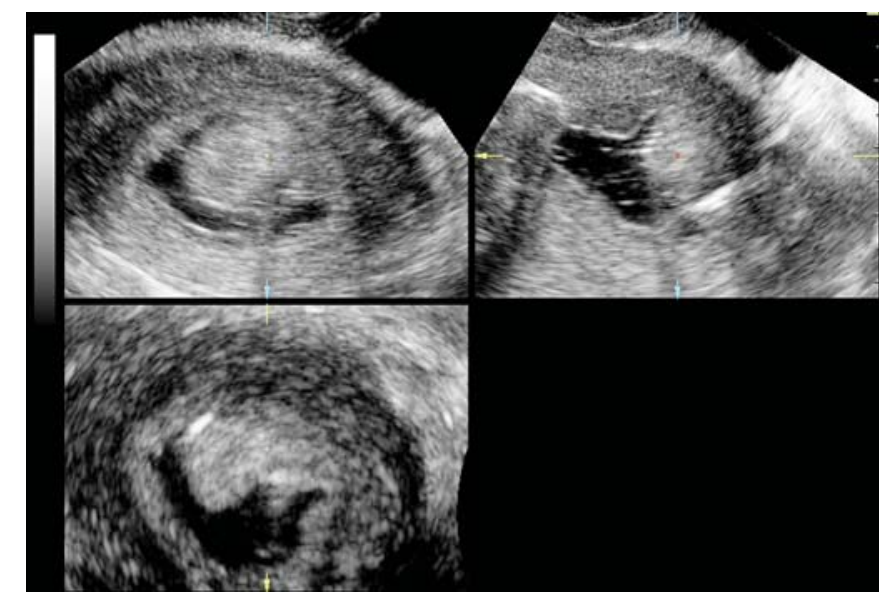

Fig. 13: Three-dimensional sonohysterography in a case of submucous myoma

of uterine leiomyomas use to be a hypoechoic rounded or oval well-defined lesion arising from the myometrium. Sometimes, some secondary changes may occur with a wide spectrum of ultrasonic images.

The use of 3D ultrasound in the assessment of uterine fibroids has been evaluated in few studies.

Salim et al found that 3D sonohysterography is very useful to classify submucous myomas and the agreement with the hysteroscopic classification is high ( $\mathrm{K}$ appa index $=$ 0.81) (Fig. 13). ${ }^{35}$

We also have found that 3D multiplanar display of submucous myomas is very useful to determine the myometrial safety margin prior to hysteroscopic resection (Fig. 14).

The assessment of leiomyoma vascularity by 3D PD ultrasound allows the assessment of its vascular network. This assessment clearly shows that typical vascular network of uterine fibroids has a 'nest' appearance (Fig. 15). Their findings are in agreement with those studies based on corrosion analysis of vascular network. ${ }^{36}$

One possible clinical application of this technique is its use for predicting response to medical treatment. M uñiz

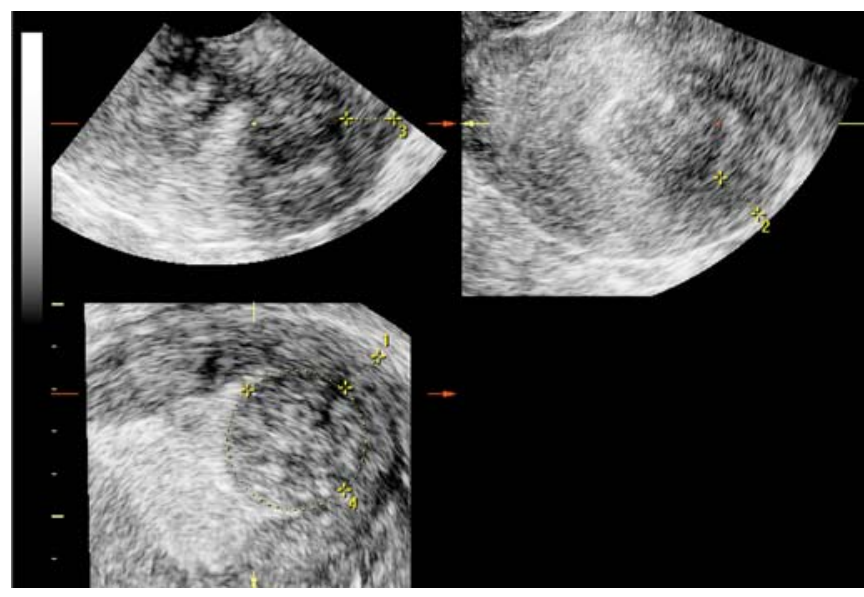

Fig. 14: Estimation of safety margin for hysteroscopic resection in a case of submucous myoma using 3D multiplanar navigation 
et al assessed 15 women with uterine fibroids prior to uterine artery embolization by 3D PD USG ${ }^{37}$ and concluded that this technique can reveal collateral blood flow not detected by uterine artery arteriography and could predict response to treatment.

Exacoustos evaluated and compared the role of 2D and 3D ultrasound before, during and after laparoscopic cryomyolysis in 10 women with uterine fibroid. ${ }^{38}$ The authors used a semi-quantitative assessment of blood flow at the level of the fibroid capsule and inside the tumor. This study found that both, 2D and 3D power Doppler ultrasound was useful to assess fibroid vascularization but 3D power Doppler were best to evaluate such an evaluation.

The preoperative diagnosis of uterine sarcoma remains a formidable clinical challenge. A ttempts have been made for such diagnosis using 3D PD USG. K upesic et al reported that typical vascularization of uterine sarcoma was characterized by irregular vessels that were randomly dispersed both in central parts of the tumor. ${ }^{39}$ However, this findings can also be found in growing large benign fibroids (Fig. 16)

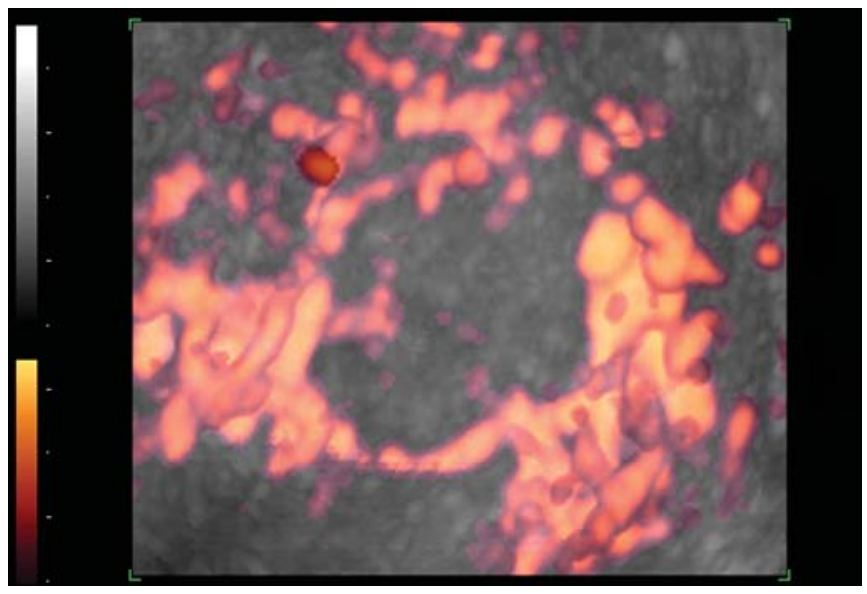

Fig. 15: 'Nest' appearance of the vascular network of uterine fibroid by 3D PD

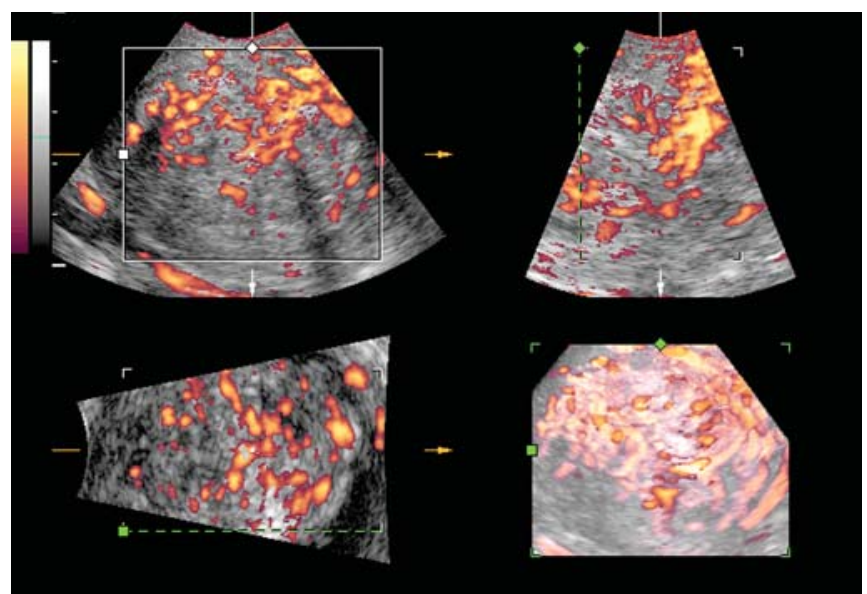

Fig. 16: Chaotic vascular network in a fast growing uterine fibroid
In conclusion, 3D PD USG seems to be a potential tool for predicting response to medical treatment of uterine fibroids and to assess their grow th potential. Its role in the diagnosis of uterine sarcoma remains to be established.

\section{CERVICAL CANCER}

Suren et al were the first to report the assessment of intracervical vascularization by 3D PD USG. ${ }^{40}$ They found that the typical finding in cases of cervical cancer a chaotic network with tortuous vessels as compared with benign conditions in which the course of vessels has a regular structure (Figs 17 and 18).

This technique can assess precisely tumor volume and vascularization (Figs 19 and 20).

$\mathrm{H}$ su et $\mathrm{al}^{41}$ analyzed 141 w omen with early stage cervical cancer. They described four types of intratumoral vascularity patterns, which were not correlated with vascularization index (VI), vascularization flow index (VFI) and flow index (FI) values: localized, peripheral, scattered and singlevessels types. Tumor volume was related to $\mathrm{FI}(r=0.373$, $p<0.001$ ), but not with VI or VFI. They concluded that

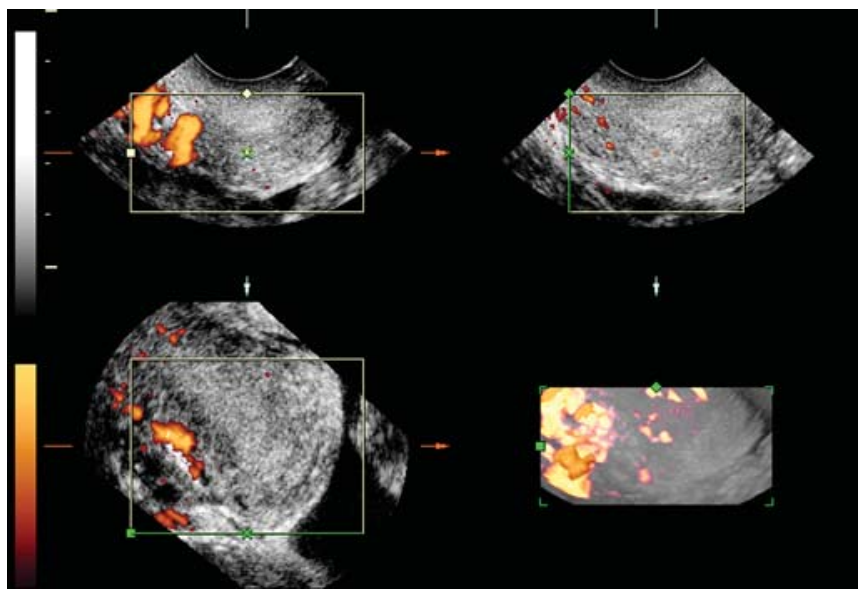

Fig. 17: Three-dimensional power Doppler appearance of cervical vascularity in a case of uterine cervix without pathology

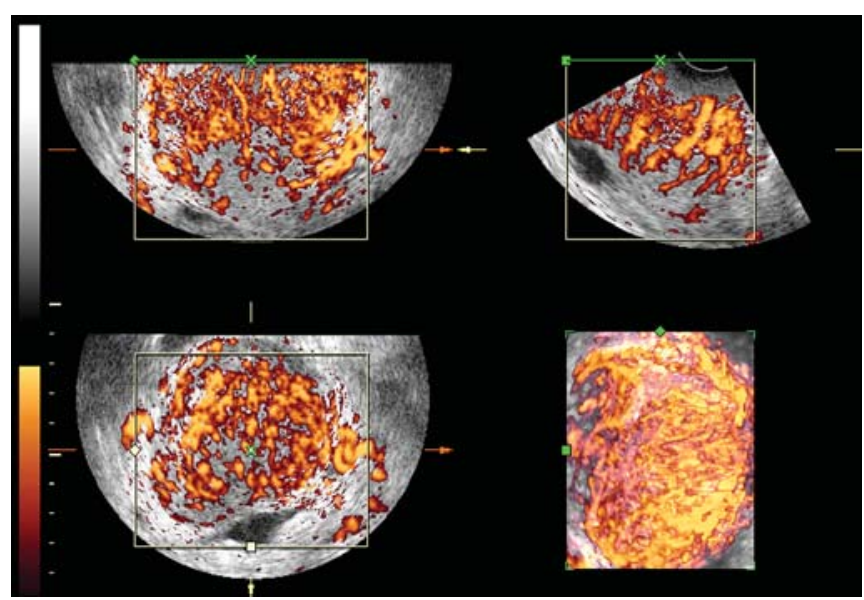

Fig. 18: Three-dimensional power Doppler appearance of cervical vascularity in a case of uterine cervical cancer 


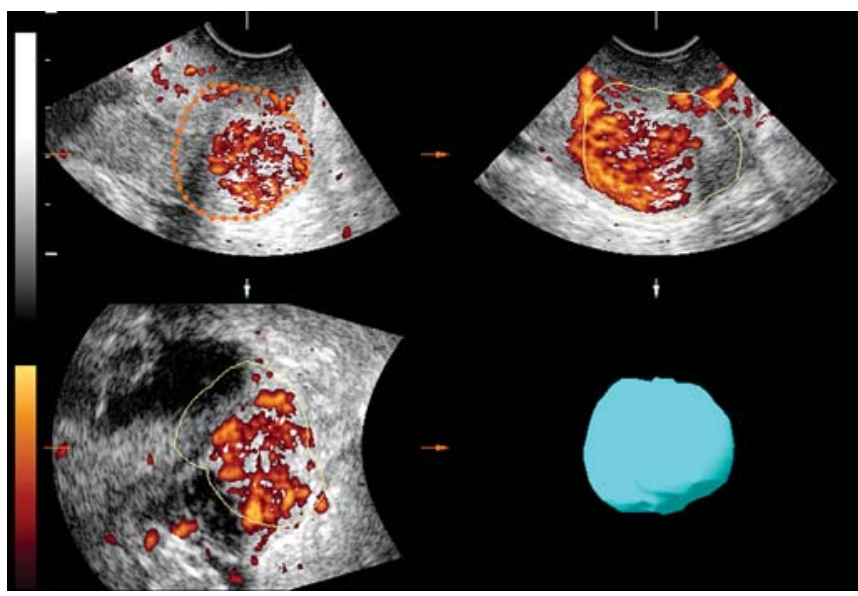

Fig. 19: Tumor volume calculation in cervical cancer by using the VOCAL rotational method

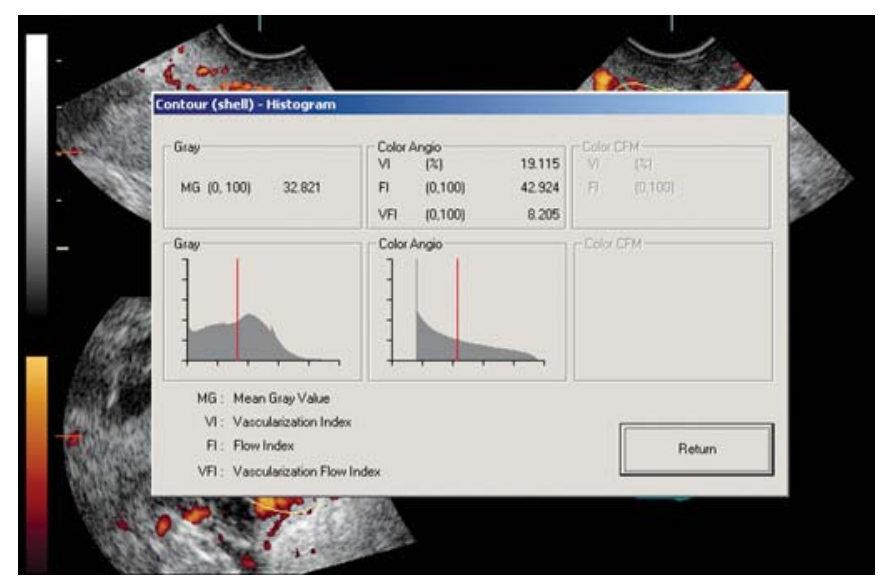

Fig. 20: Three-dimensional power Doppler indices calculated in a case of cervical cancer

this technique was a useful tool to investigate intratumoral vascularization.

However, Testa et al ${ }^{42}$ did not find differences in 3D power Doppler blood flow parameters in cervical cancer according to tumor diameter, tumor grade and histological type. They found a marginal statistical significant according to tumor stage, being III/IV stages more vascularized than I/II stages tumors.

In our experience, a progressive increase in $\mathrm{VI}, \mathrm{VFI}$ and FI exists in patients with no cervical pathology, intraepithelial neoplasia and invasive cervical cancer. ${ }^{43} \mathrm{We}$ reported data on 56 women with cervical cancer. ${ }^{44} \mathrm{No}$ correlation was found between tumor volume and 3D-PDA indexes with histologic type, lymphovascular space invasion (LVSI) and lymph node metastases. M oderately and poorly differentiated tumors and advanced stage tumors had larger volume and higher 3D-PDA indexes.

Although, the clinical value of 3D-PDA assessment of tumor vascularization in cervical cancer still needs to be established all these studies pointed out that the noninvasive assessment of tumor vascularity prior to treatment could be useful to identify high-risk patients for recurrence. In fact, some preliminary data show that it may be useful for assessing tumor response to chemoradiation in advanced cancer. ${ }^{45}$

One study described a novel technique using 3D ultrasound for local staging of cervical carcinoma. ${ }^{46}$ This method was based on the multiplanar display and was used in 14 women. The concordance of 3D ultrasound and pathology for assessing parametrial, rectum and bladder involvement was 93\%, 93 and 100\% respectively.

\section{Adnexal Tumors}

Three-dimensional ultrasonography overcomes some limitations of conventional 2D ultrasound allowing a more detailed assessment of morphologic features of the object studied, with no restriction to the number and orientation of the scanning planes.

A mong the advantages of 3D ultrasound are the possibilities of obtaining images from all spatial planes and eliminate echoes by using the 'threshold' function. The first allows a more detailed assessment of intracystic structures and the second allows eliminating internal echoes mimicking solid tissue, such as clots, debris and fatty and mucinous plugs (Fig. 21). In our experience, surface rendering was the most useful mode for 3D TV S evaluation (Fig. 22). The 'niche mode' may be also helpful in some instances (Figs 23A and B). However, some pitfalls when using 3D transvaginal ultrasound (TVS) might be born in mind. By using the surface rendering mode alone some daughter cysts may be interpreted as solid areas. On the other hand, threshold function works similarly to gain in conventional 2D ultrasound. A $n$ excessive gain adjusting may eliminate some true solid areas, leading to reclassify as benign an actually malignant lesion.

A new image display modality is the 'inversion mode', which can be depicted as 'solid', the cystic components of the tumor. This could be helpful in predominantly cystic complex lesions such as hydrosalpinx (Fig. 24).

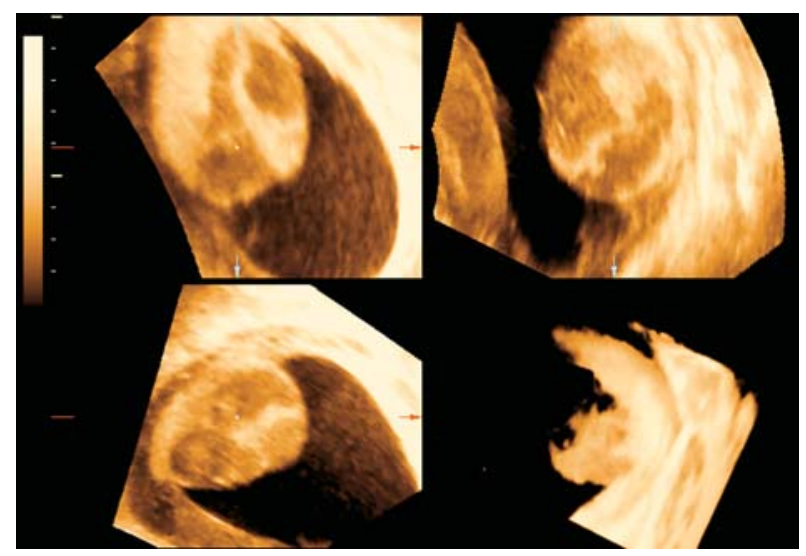

Fig. 21: The use of the 'threshold' function allows eliminating some internal echoes in a case of cystic dermoid tumor 


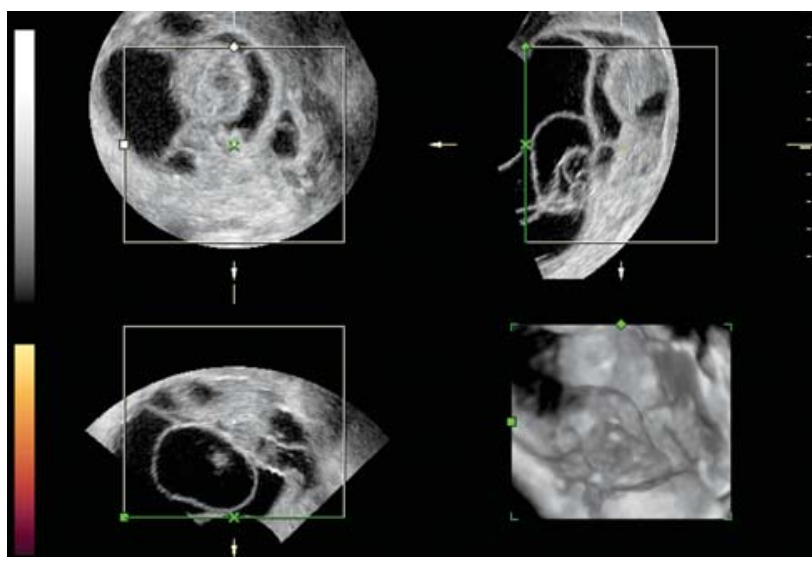

Fig. 22: Three-dimensional surface rendering of the internal appearance in an ovarian multilocular cyst with solid components
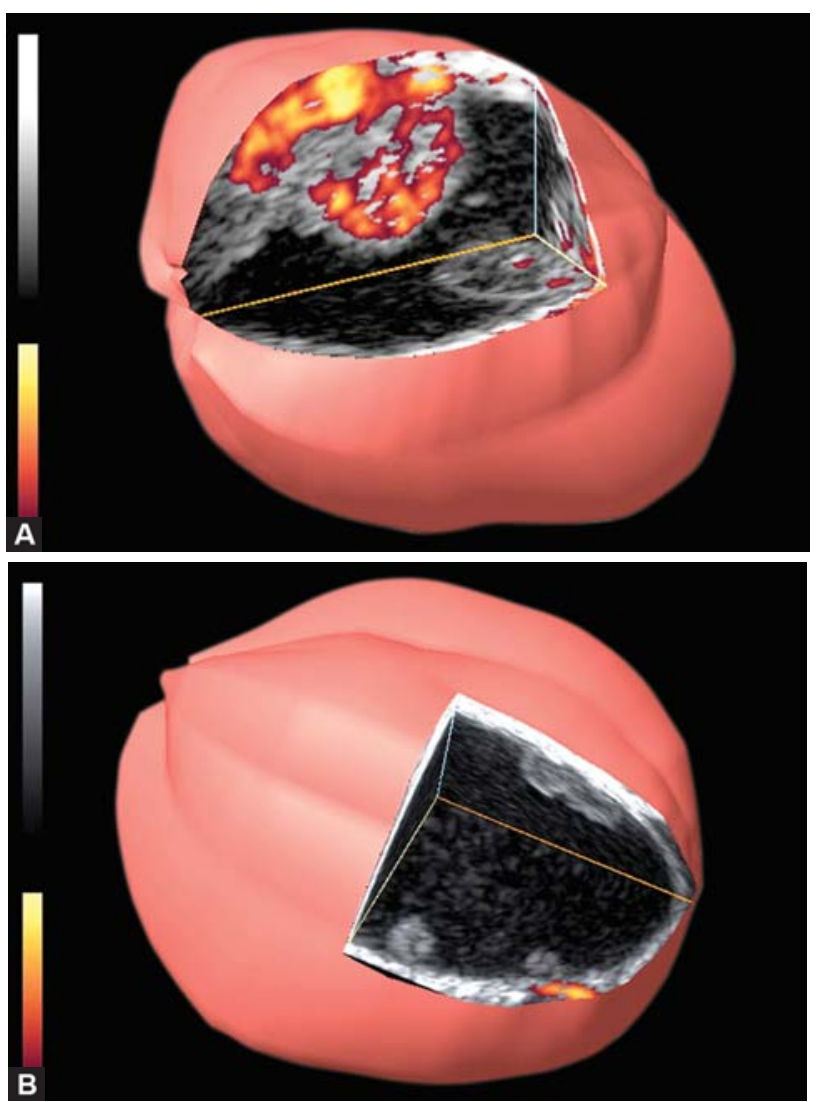

Figs 23A and B: Two cases of ovarian cyst with a gross papillary projection. In case A, 'niche' mode allows confirming that vessels coming from the cyst wall enter the papillary projection. In case $B$, it can be seen how no vessels appear within the papillary projection. (Courtesy: Dr MA Pascual)

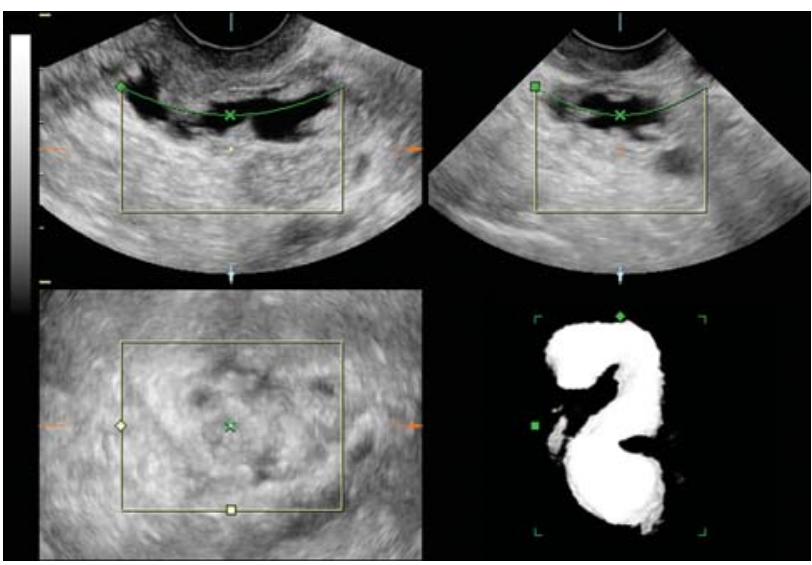

Fig. 24: Three-dimensional reconstruction of a hydrosalpinx by using the 'inversion mode'. The shape of the tube is clearly shown

Studies evaluating the role of 3D TVS in assessing adnexal masses are scanty and reported controversial results (Table 2).

B onilla-M usoles et al evaluated by 2D and 3D ultrasonography, 76 women diagnosed as having an adnexal mass. They concluded that 3D TVS was more sensitive than 2D TVS. ${ }^{47}$

Hata et al compared 3D TV S with 2D TVS in 20 patients with adnexal masses. They found that 3D TVS was more specific than 2D TVS. ${ }^{48}$

M ore recently, K urjak reported the results of a study comparing five different sonographic techniques in a series of 251 adnexal tumors. They found 3D TV S more sensitive than 2D TVS with similar specificity. ${ }^{22}$

We found that 3D ultrasonography had not statistically better diagnostic performance than 2D in a series of 44 selected complex adnexal masses. ${ }^{49}$ We found 3D TVS useful to reinforce initial diagnostic impression. In a second series, we found similar results to the previous one ${ }^{50}$ In this second study, we showed that 3D USG had a good intraand interobserver reproducibility for assessing adnexal masses. $^{50}$

These controversial results might be explained by the fact that in the first two studies the number of malignant tumors was small and probably because all of them, except

\begin{tabular}{|c|c|c|c|c|c|c|c|}
\hline \multirow{2}{*}{ Author } & \multirow[t]{2}{*}{$\mathrm{N}$} & \multirow{2}{*}{ OC prevalence (\%) } & \multicolumn{2}{|c|}{ Sensitivity } & \multicolumn{2}{|c|}{ Specificity } & \multirow{2}{*}{$p$-value } \\
\hline & & & $3 \mathrm{D}(\%)$ & $2 \mathrm{D}(\%)$ & 3D (\%) & $2 \mathrm{D}(\%)$ & \\
\hline Bonilla 47 & 76 & 7 & 100 & 80 & 100 & 99 & $<0.05$ \\
\hline Hata 48 & 20 & 25 & 100 & 100 & 92 & 38 & $<0.05$ \\
\hline Alcazar 49 & 49 & 48 & 100 & 90 & 78 & 61 & NS \\
\hline Alcazar 50 & 82 & 33 & 93 & 89 & 98 & 94 & NS \\
\hline
\end{tabular}

OC: ovarian cancer; 2D: two-dimensional ultrasound; 3D: three-dimensional ultrasound; NS: statistically nonsignificant 
ours, included many not complex tumors. On the other hand, the sonographic criteria for malignant suspicion on 3D USG were the same than in 2D USG.

With the advent of 3D USG, 3D PD imaging has also become available for clinical practice. This techniqueallows tumor vascularization assessment, both quantitatively by means of 3D PD USG-derived vascular indexes and qualitatively by depicting three-dimensionally the tumor vascular network.

Kurjak et al in two different studies on 120 and 90 adnexal masses, respectively, concluded that 3D PD was superior to conventional color Doppler by increasing the sensitivity. ${ }^{51,52}$ This same group found that the use on sonographic contrast agents would improve even more the performance of 3D Power Doppler. ${ }^{53}$ They compared a scoring system that included some morphological features and 3D PD evaluation of tumor vessels characteristics, such as vessels arrangement and branching pattern, with another scoring system that included the same morphological

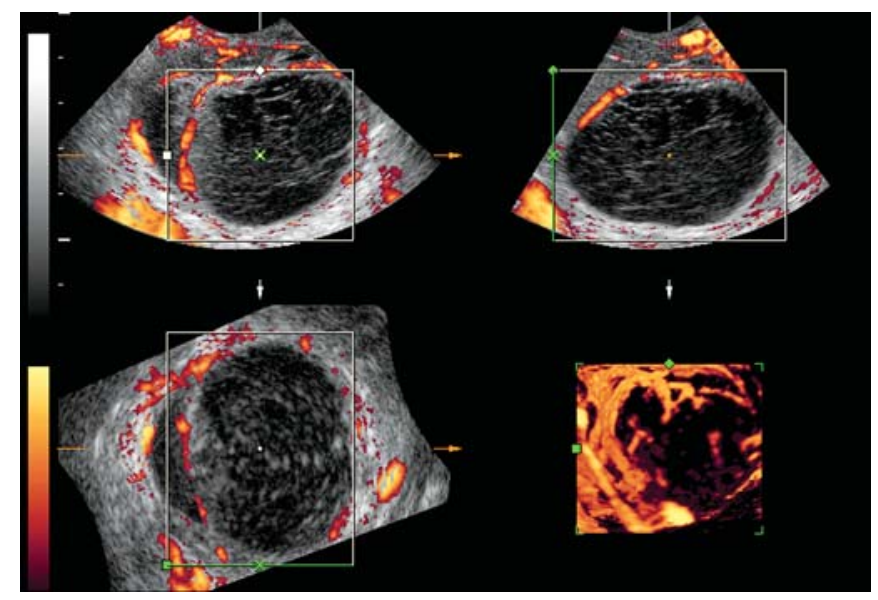

Fig. 25: Three-dimensional power Doppler depiction of the vascular network from a benign ovarian cystic tumor features with pulsed Doppler velocimetric parameters ( $\mathrm{R}$ I $<0.42$ or $>0.42$ ). They based their diagnostic criteria for malignancy suspicion on vessel architecture as depicted by 3D such as branching pattern, vessel caliber and presence of microaneurysms or vascul ar lakes (Figs 25 and 26). This was based on the chaos theory, ${ }^{54}$ which establish that vascular architecture of a vascular network of newly formed vessels in malignant tumors is built following a chaotic distribution but not in a predetermined fashion. Although, this has been demonstrated in corrosion studies, ${ }^{55}$ the reproducibility of this approach is just moderate. ${ }^{56}$

Several subsequent studies, using all of them similar criteria for malignancy suspicion, reported similar findings: 3D PD vascular tree assessment adds little to conventional ultrasound. ${ }^{57-60}$ These studies are summarized in Table 3.

Cohen et al evaluated the role of 3D PD in a series of 71 complex adnexal masses on 2D TVS. ${ }^{61}$ They did not use 2D conventional color Doppler nor 2D PD. In their approach, they combined 2D and 3D morphological features

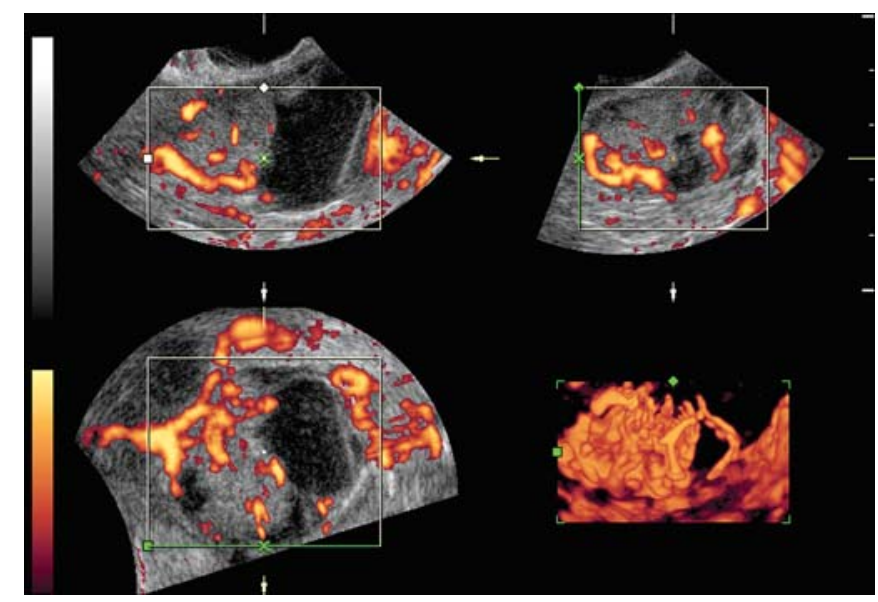

Fig. 26: Three-dimensional power Doppler depiction of the vascular network from a malignant ovarian tumor

Table 3: Three-dimensional power Doppler tumor vascular tree assessment for diagnosing ovarian cancer

\begin{tabular}{|c|c|c|c|c|c|c|c|}
\hline \multirow[t]{2}{*}{ Author } & \multirow[t]{2}{*}{$\mathrm{N}$} & \multirow{2}{*}{$\begin{array}{l}\text { OC prevalence } \\
(\%)\end{array}$} & \multicolumn{2}{|c|}{ Sensitivity } & \multicolumn{2}{|c|}{ Specificity } & \multirow[t]{2}{*}{$\mathrm{p}$-value } \\
\hline & & & 3D PD (\%) & $2 \mathrm{D}(\%)$ & 3D PD (\%) & 2D (\%) & \\
\hline Kurjak $^{51 \dagger}$ & 120 & 9 & 100 & 91 & 99 & 97 & NS \\
\hline Kurjak $^{52 \dagger}$ & 90 & 10 & 100 & 89 & 99 & 37 & NS \\
\hline Laban ${ }^{57 \dagger^{*}}$ & 50 & 62 & 100 & 100 & 74 & 74 & NS \\
\hline Sladkevicius ${ }^{58 \neq}$ & 104 & 26 & 96 & 100 & 96 & 90 & NS \\
\hline Alcazar ${ }^{56 \S}$ & 39 & 51 & 90 & 95 & 74 & 74 & NS \\
\hline Dai ${ }^{59 \S *}$ & 36 & 83 & 77 & 97 & 50 & 50 & $<0.05$ \\
\hline Mansour ${ }^{60 \S}$ & 400 & 62 & 88 & 94 & 89 & 73 & NS \\
\hline
\end{tabular}

OC: ovarian cancer; 2D: two-dimensional ultrasound; 3D PD: three-dimensional power Doppler; NS: statistically nonsignificant; ${ }^{\dagger} \mathrm{Criteria}$ for malignancy suspicion: scoring system combining morphology and 3D PD features; ${ }^{\ddagger}$ C riteria for malignancy suspicion: logistic model combining morphology and 3D PD features; ${ }^{\S} \mathrm{C}$ riteria for malignancy suspicion: only 3D PD features; *Only 'complex' masses included in the study 
with 3D PD evaluation of blood flow tumor location, considering a tumor as malignant in the presence of complex morphological pattern and central (in papillary projections and/or septations) blood flow location. They concluded that the addition of 3D PD improved the specificity of 2D TVS (75 vs $54 \%$ ), without decreasing the sensitivity. Similar results have been recently reported by $\mathrm{G}$ eomini et al. ${ }^{62}$ These results are not surprising and can be achieved also by using a simpler technique such as color Doppler. ${ }^{18}$

We found that the diagnostic performance of 3D PD was not statistically better than that of $2 D P D$ in a series of 69 complex adnexal masses, presenting both techniques similar sensitivity (97.8\% for both techniques) and specificity (87 vs $79 \%$ ). ${ }^{63}$ We compared the $2 \mathrm{D} P D$ diagnostic criteria proposed by Guerriero et al ${ }^{18}$ with the 3D PD diagnostic criteria proposed by K urjak et al. ${ }^{22}$

However, when a complex mass with detectable blood flow within solid areas or thick papillary projections is found, it should be categorized mass as 'malignant' or 'highly suspicious'. However, a considerable number of benign tumors may exhibit this appearance, for example, cystadenofibroma, tuboovarian abscess or solid benign ovarian tumor.

Using conventional 2D color or power Doppler we have no means to differentiate these benign entities from true malignant tumors. Three-dimensional power Doppler ultrasound provides a new approach to assess tumor vascularization. We have termed this new approach '3D PD vascular sampling'. ${ }^{64}$ It consists of assessing the vascularization of a given suspicious area in a given tumor by calculating 3D PD-derived indexes within these areas (Figs 27 and 28). In a series of 49 vascularized complex adnexal masses, we found that 3D PD-derived indexes were significantly higher in malignant tumors as compared with benign ones. Pulsed Doppler indexes were not helpful. A Imost simultaneously to our study, Testa et al published a

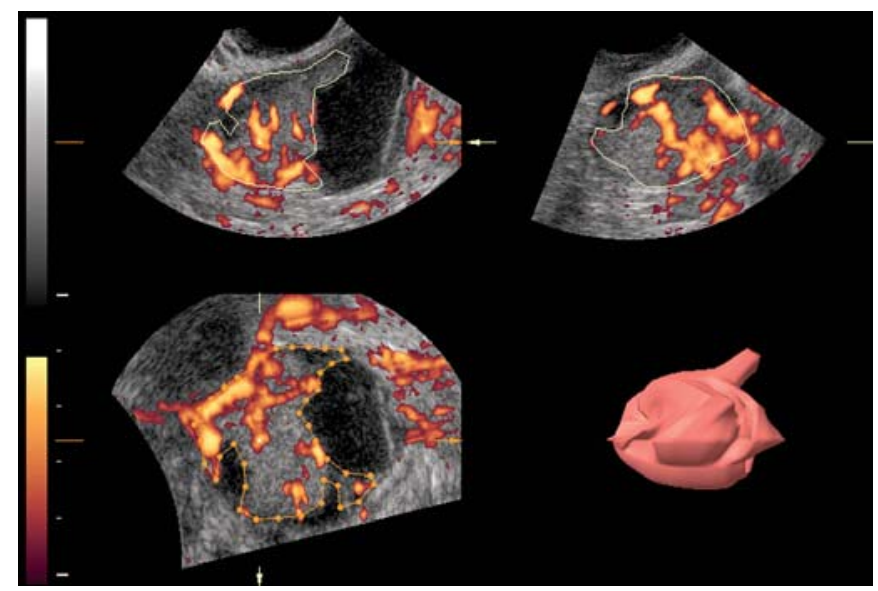

Fig. 27: Volume calculation from the solid portion from a cysticsolid ovarian tumor study on 24 solid pelvic masses with basically identical results to ours. ${ }^{65}$

A fter these pioneering reports, Geomini et al reported data from a series of 181 women with adnexal masses using the method proposed by A Icazar. ${ }^{62}$ This group included any kind of mass diagnosed at TVS and performed the vascular assessment from the whole tumor. They found that FI, but not VI and VFI, was significantly higher in ovarian cancer.

Jokubkiene et al proposed a modified approach based on the use of a virtual $5 \mathrm{cc}$ spherical sampling from the most vascularized area from the tumor. They also found that 3D PD vascular indexes were higher in ovarian cancer as compared with benign tumors. ${ }^{66}$ Similar results were reported by $K$ udla et al but using a 1 cc spherical sampling. ${ }^{67}$

The only study that has not shown differences in 3D PD indexes between benign and malignant ovarian tumors was reported by Ohel et al. ${ }^{68} \mathrm{H}$ owever, the series was too small (only 17 cases) and the methods used were not fully explained.

Alcazar and Prka compared manual and spherical sampling and concluded that both methods are comparable and that spherical sampling is faster to perform but cannot be used in some small tumors. ${ }^{69}$ This may be solved using 1 cc sphere. ${ }^{67}$

Several studies have shown that, whatever the approach used, manual or spherical sampling, reproducibility is high between observers. ${ }^{69-71}$

Regarding to the contribution to diagnosis of ovarian cancer, Geomini et al reported a multicenter prospective study concluding that the use of 3D ultrasound significantly improves the prediction of malignancy as compared to $2 \mathrm{D}$ ultrasonography. ${ }^{72}$ Alcazar et $\mathrm{al}^{73}$ and $\mathrm{K}$ udla et al ${ }^{74}$ have shown that $3 D$ PD may decrease false-positive rate of $2 D$ PD in solid and cystic-solid adnexal masses. However, Joubkiene et al concluded that 3D PD does not add more

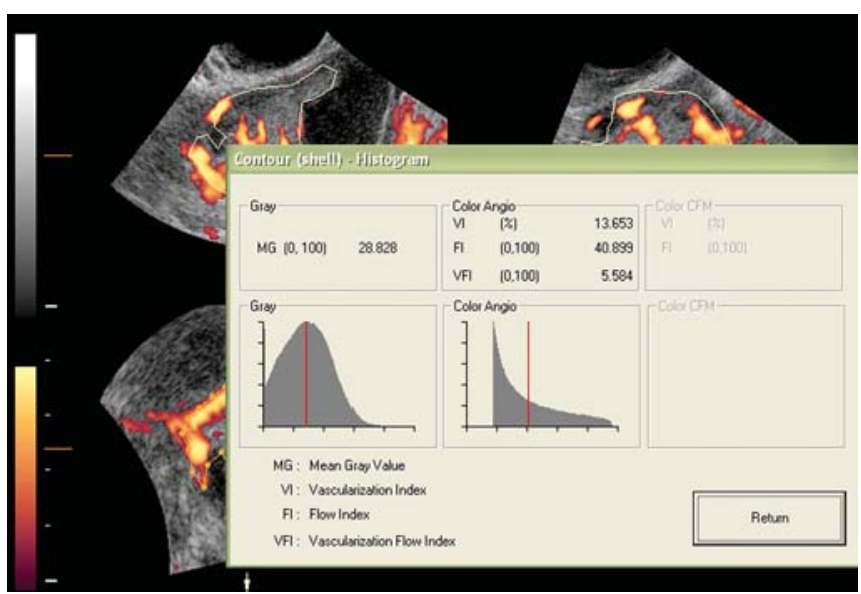

Fig. 28: Three-dimensional power Doppler derived vascular indices from the solid component (vascular sampling) from the case of the previous figure 
Three-dimensional Static Ultrasound and 3D Power Doppler in Gynecologic Pelvic Tumors

Table 4: Three-dimensional power Doppler vascular sampling for diagnosing ovarian cancer

\begin{tabular}{|c|c|c|c|c|c|c|c|}
\hline \multirow[t]{2}{*}{ Author } & \multirow[t]{2}{*}{$\mathrm{N}$} & \multirow{2}{*}{$\begin{array}{l}\text { OC prevalence } \\
(\%)\end{array}$} & \multicolumn{2}{|c|}{ Sensitivity } & \multicolumn{2}{|c|}{ Specificity } & \multirow[t]{2}{*}{$p$-value } \\
\hline & & & 3D PD\% & $2 \mathrm{D} \%$ & 3D PD\% & $2 \mathrm{D} \%$ & \\
\hline Geomini62† $^{62 \dagger}$ & 181 & 20 & 57 & 91 & 85 & 63 & $<0.05$ \\
\hline J okubkiene ${ }^{66 \dagger}$ & 106 & 25 & 100 & 100 & 92 & 90 & $<0.05$ \\
\hline Alcazar ${ }^{73 * \$}$ & 143 & 74 & 95 & 100 & 33 & 0 & $<0.05$ \\
\hline Kudla ${ }^{74 * \S}$ & 138 & 82 & 91 & 100 & 77 & 0 & $<0.05$ \\
\hline Guerriero ${ }^{75 * \S}$ & 35 & 71 & 68 & 100 & 40 & 0 & $<0.05$ \\
\hline
\end{tabular}

OC: ovarian cancer; 2D: two-dimensional ultrasound; 3D-PD: three-dimensional power Doppler; ${ }^{\dagger}$ Criteria for malignancy suspicion: logistic system combining morphology and 3D PD indexes; ${ }^{\S} \mathrm{Criteria}$ for malignancy suspicion: only 3D PD indexes; *Only 'complex' masses included in the study

information to gray-scale imaging than that provided by subjective quantification by $2 \mathrm{D} \mathrm{PD} .{ }^{67} \mathrm{G}$ uerriero et al found that the use of 3D PD increased the specificity of ultrasound in suspicious masses but also decreased significantly the sensitivity. ${ }^{75}$ These studies are summarized in Table 4.

Furthermore, we have recently demonstrated that vascularization, as assessed by 3D PD vascular indexes, is higher in advanced stage and metastatic ovarian cancers than in early stage ovarian cancer. ${ }^{76}$ These preliminary results may be valuable for future research. It would be worth exploring if 3D PD-derived vascular indexes in ovarian cancer could be used as prognostic factor in ovarian cancer.

\section{Other Applications}

Three-dimensional ultrasound has been proposed as a means for monitoring the response to treatment in gynecologic malignancies.

Y aman and Fridrik reported on one case of cervical cancer and one case of ovarian cancer evaluated by $3 \mathrm{D}$ power Doppler ultrasound before and after treatment with radio- and /or chemotherapy. They observed a reduction of tumor volume, $\mathrm{VI}, \mathrm{FI}$ and $\mathrm{V} \mathrm{FI}$ in both cases after treatment. ${ }^{77}$

Su et al reported on one case of primary papillary serous carcinoma of the peritoneum evaluated by 3D PD USG before and after treatment with chemotherapy. They also reported that tumor volume and 3D PD indices decreased progressively during treatment. ${ }^{78}$

\section{REFERENCES}

1. Smith-Bindman R, Kerlikowske K, Feldstein VA, et al. Endovaginal ultrasound to exclude endometrial cancer and other endometrial abnormalities. JA M A 1998;280:1510-17.

2. Kurjak A, Shalan $H$, Sosic $A$, et al. Endometrial carcinoma in postmenopausal women: Evaluation by transvaginal color Doppler ultrasonography. Am J Obstet Gynecol 1993;169: 1597-603.
3. Sladkevicius $P, V$ alentin $L, M$ arsal $K$. Endometrial thickness and $D$ oppler velocimetry of the uterine arteries as discriminators of endometrial status in women with postmenopausal bleeding: A comparative study. A m J Obstet Gynecol 1994;171:722-28.

4. A lcazar J L, Castillo G, M inguez JA, et al. J Endometrial blood flow mapping using transvaginal power Doppler sonography in women with postmenopausal bleeding and thickened endometrium. Ultrasound O bstet Gynecol 2003;21:583-88.

5. Alcazar J L, A jossa S, Floris S, et al. Reproducibility of endometrial vascular patterns in endometrial disease as assessed by transvaginal power Doppler sonography in women with postmenopausal bleeding. J Ultrasound M ed 2006;25:159-63.

6. A leen F, Predanic M. U terine leiomyoma: Transvaginal color Doppler studies and new aspects of management. In: Osmers $R, K$ urjak A (Eds). U Itrasound and the uterus. L ondon: Parthenon Publishing Group 1995;61-70.

7. A lcázar J L, G riffioen M, J urado M. U terine artery blood flow in women with uterine myomas. Eur J Ultrasound 1997;5: 165-69.

8. K urjak A, K upesic S, Shalan H, et al. U terine sarcoma: A report of 10 cases studied by transvaginal color and pulsed Doppler sonography. Gynecol Oncol 1995;59:342-46.

9. Szabo I, Szantho A, Csabay L, et al. Color Doppler ultrasonography in the differentiation of uterine sarcomas from uterine leiomyomas. Eur J Gynaecol Oncol 2002;23:29-34.

10. A viram $R, O$ chshorn $Y, M$ arkovitch $O$, et al. U terine sarcomas versus leiomyomas: Gray-scale and Doppler sonographic findings. J Clin Ultrasound 2005;33:10-13.

11. A lcázar J L, Castillo G, J urado M, et al. Intratumoral blood flow in cervical cancer as assessed by transvaginal color Doppler ultrasonography: Correlation with tumor features. IntJ Gynecol Cancer 2003;13:510-14.

12. Alcázar JL, Jurado M. Transvaginal colour Doppler for predicting pathological response to preoperative chemoradiation in locally advanced cervical carcinoma: A preliminary study. Ultrasound M ed Biol 1999;25:1041-45.

13. Engelen M J, K os HE, Willemse PH, et al. Surgery by consultant gynecologic oncologists improves survival in patients with ovarian carcinoma. Cancer 2006;106:589-98.

14. Canis $M$, Rabischong B, Houlle $C$, et al. Laparoscopic management of adnexal masses: A gold standard? Curr O pin Obstet Gynecol 2002;14:423-28.

15. A lcázar J L, Castillo G, J urado M, et al. Expectant management of sonographically benign ovarian cysts in asymptomatic premenopausal women. Human Reprod 2005;20:3231-34.

16. K inkel $\mathrm{K}, \mathrm{H}$ ricak $\mathrm{H}, \mathrm{L}$ u Y, et al. US characterization of ovarian masses: A meta-analysis. Radiology 2000;217:803-11. 
17. Tekay A, J ouppila P. Controversies in assessment of ovarian tumors with transvaginal color Doppler ultrasound. A cta Obstet Gynecol Scand 1996;75:316-29.

18. Guerriero S, A lcázar J L, Coccia M E, et al. Complex pelvic mass as a target of evaluation of vessel distribution by color Doppler for the diagnosis of adnexal malignancies: R esults of a multicenter European study. J Ultrasound M ed 2002;21:1105-11.

19. Alcázar JL. Three-dimensional ultrasound in gynecology: Current status and future perspectives. Curr W omen's Health Rev 2005;1:1-14.

20. Alcázar JL, M ercé LT, García-M anero M, et al. Endometrial volume and vascularity measurements by transvaginal threedimensional ultrasonography and power Doppler angiography in stimulated and tumoral endometria: An interobserver reproducibility study. J Ultrasound M ed 2005;24:1091-98.

21. Gruboeck $K$, J urkovic $D$, L awton $F$, et al. The diagnostic value of endometrial thickness and volume measurements by threedimensional ultrasound in patients with postmenopausal bleeding. Ultrasound O bstet Gynecol 1996;8:272-76.

22. Kurjak $A$, K upesic $S$, Sparac $V$, et al. Preoperative evaluation of pelvic tumors by $D$ oppler and three-dimensional sonography. J Ultrasound M ed 2001;20:829-40.

23. Mansour GM, El-Lamie IK, El-Kady M A, et al. Endometrial volume as predictor of malignancy in women with postmenopausal bleeding. Int J Gynaecol Obstet 2007;99: 206-10.

24. Y aman C, Habelsberger A, Tews $\mathrm{G}$, et al. The role of threedimensional volume measurement in diagnosing endometrial cancer in patients with postmenopausal bleeding. Gynecol Oncol 2008;110:390-95.

25. Odeh M, Vainerovsky I, Grinin V, et al. Three-dimensional endometrial volume and three-dimensional power Doppler analysis in predicting endometrial carcinoma and hyperplasia. Gynecol Oncol 2007;106:348-53.

26. M ercé $L T, A$ lcázar JL, L ópez $C$, et al. Clinical usefulness of three-dimensional sonography and power Doppler angiography for diagnosis of endometrial carcinoma. J Ultrasound Med 2007;26:1279-87.

27. Opolskiene $G$, Sladkevicius $P$, J okubkiene $L$, et al. Threedimensional ultrasound imaging for discrimination between benign and malignant endometrium in women with postmenopausal bleeding and sonographic endometrial thickness of at least $4.5 \mathrm{~mm}$. Ultrasound Obstet Gynecol 2010;35: 94-102.

28. Alcazar JL, Galvan R. Three-dimensional power Doppler ultrasound scanning for the prediction of endometrial cancer in women with postmenopausal bleeding and thickened endometrium. A m J Obstet Gynecol 2009;200:44.e1-6.

29. Bonilla-M usoles F, Raga F, Osborne NG, et al. Threedimensional hysterosonography for the study of endometrial tumors: Comparison with conventional transvaginal sonography, hysterosalpingography and hysteroscopy. Gynecol Oncol 1997;65:245-52.

30. Su MT, Su RM , Y ue CT, et al. Three-dimensional transvaginal ultrasound provides clearer delineation of myometrial invasion in a patient with endometrial cancer and uterine leiomyoma. Ultrasound Obstet Gynecol 2003;22:434-36.

31. Alcázar J L, Galván R, A lbela $S$, et al. A ssessing myometrial infiltration by endometrial cancer: Uterine virtual navigation with three-dimensional US. Radiology 2009;250:776-83.
32. Pairleitner $H$, Steiner $H, H$ asenoehrl $G$, et al. Three-dimensional power Doppler sonography: I maging and quantifying blood flow and vascularization. Ultrasound Obstet Gynecol 1999;14: 139-43.

33. Kupesic S, Kurjak A, Zodan T. Staging of the endometrial carcinoma by three-dimensional power Doppler ultrasound. Gyneacol Perinatol 1999;8:1-7.

34. Galván $R$, M ercé $L$, Jurado $M$, et al. Three-dimensional power Doppler angiography in endometrial cancer: Correlation with tumor characteristics. Ultrasound Obstet Gynecol 2010;35: 723-29.

35. Salim R, Lee C, Davies A, et al. A comparative study of threedimensional saline infusion sonohysterography and diagnostic hysteroscopy for the classification of submucous fibroids. Hum Reprod 2005;20:253-57.

36. Walocha JA, Litwin JA, Miodonski AJ. Vascular system of intramural leiomyomata revealed by corrosion casting and scanning electron microscopy. Hum Reprod 2003;18:1088-93.

37. M uniz CJ , Fleischer A C, Donnelly EF, et al. Three-dimensional color Doppler sonography and uterine artery arteriography of fibroids: A ssessment of changes in vascularity before and after embolization. J Ultrasound M ed 2002;21:129-33.

38. Exacoustos $C$, Zupi $E, M$ arconi $D$, et al. Ultrasound-assisted laparoscopic cryomyolysis: Tw o- and three-dimensional findings before, during and after treatment. U Itrasound O bstet Gynecol 2005;25:393-400.

39. Kupesic S, Kurjak A. Three-dimensional power Doppler ultrasound examination of uterine lesions. In: Kurjak A (Ed) Three-dimensional power-D oppler in obstetrics and gynecology. L ondon: Parthenon Publishing G roup 2000:39-52.

40. Suren A, Osmers R, K uhn W. 3D color power angio imaging: A new method to assess intracervical vascularization in benign and pathological conditions. UItrasound Obstet Gynecol 1998;11:133-37.

41. Hsu KF, Su JM, Huang SC, et al. Three-dimensional power Doppler imaging of early-stage cervical cancer. Ultrasound Obstet Gynecol 2004;24:664-71.

42. Testa A C, Ferrandina G, Distefano M, et al. Color Doppler velocimetry and three-dimensional color power angiography of cervical carcinoma. Ultrasound Obstet Gynecol 2004;24: 445-52.

43. A lcázar JL. Transvaginal color Doppler in the assessment of cervical carcinoma. Cancer Ther 2005;3:139-46.

44. A lcázar J L, J urado M, López-García G. T umor vascularization in cervical cancer by three-dimensional power Doppler angiography: Correlation with tumor characteristics. Int J Gynecol Cancer 2010;20:393-97.

45. Tanaka K, U mesaki N. Impact of three-dimensional (3D) ultrasonography and power Doppler angiography in the management of cervical cancer. Eur J Gynaecol Oncol 2010;31:10-17.

46. Ghi T, Giunchi S, K uleva M, Santini D, Savelli L, Formelli G, Casadio P, Costa S, Meriggiola M C, Pelusi G. Threedimensional transvaginal sonography in local staging of cervical carcinoma: description of a novel technique and preliminary results. U Itrasound O bstet Gynecol 2007;30:778-82.

47. B onilla-M usoles F, Raga F, Osborne NG. Three-dimensional ultrasound evaluation of ovarian masses. Gynecol Oncol 1995;59:129-35. 
48. Hata $T, Y$ anagihara $T$, Hayashi $K$, et al. Three-dimensional ultrasonographic evaluation of ovarian tumours: A preliminary study. Hum Reprod 1999;14:858-61.

49. Alcázar J L, Galán MJ, García-M anero M, et al. Threedimensional ultrasound morphologic assessment in complex adnexal masses a preliminary experience. J Ultrasound Med 2003;22:249-54.

50. Alcázar J L, García-M anero M, Galván R. Three-dimensional sonographic morphologic assessment of adnexal masses: $A$ reproducibility study. J Ultrasound M ed 2007;26:1007-11.

51. Kurjak A, Kupesic S, Sparac V, et al. Three-dimensional ultrasonographic and power Doppler characterization of ovarian Iesions. Ultrasound Obstet Gynecol 2000;16:365-71.

52. Kurjak A, Kupesic S, A nic T, et al. Three-dimensional ultrasound and power D oppler improve the diagnosis of ovarian lesions. Gynecol Oncol 2000;76:28-32.

53. K upesic $S, K$ urjak A. Contrast-enhanced three-dimensional power D oppler sonography for differentiation of adnexal masses. Obstet Gynecol 2000;96:452-58.

54. Breyer B, Kurjak A. Tumor vascularization, Doppler measurements and chaos: What to do? Ultrasound Obstet Gynecol 1995;5:209-10.

55. Konerding MA, Miodonski AJ, Lametschwandtner A. $M$ icrovascular corrosion casting in the study of tumor vascularity: A review. Scanning M icrosc 1995;9:1233-43.

56. A lcázar J L, Cabrera C, Galván R, et al. Three-dimensional power Doppler vascular network assessment of adnexal masses: Intraobserver and interobserver agreement analysis. J U Itrasound Med 2008;27:997-1001.

57. Laban $M$, M etawee $H$, Elyan $A$, et al. Three-dimensional ultrasound and three-dimensional power Doppler in the assessment of ovarian tumors. Int J Gynaecol Obstet 2007;99:201-05.

58. Sladkevicius $P$, J okubkiene $L, V$ alentin $L$. Contribution of morphological assessment of the vessel tree by three-dimensional ul trasound to a correct diagnosis of malignancy in ovarian masses. Ultrasound Obstet Gynecol 2007;30:874-82.

59. Dai SY, Hata K, Inubashiri E, et al. Does three-dimensional power Doppler ultrasound improve the diagnostic accuracy for the prediction of adnexal malignancy? J Obstet Gynaecol Res 2008;34:364-70.

60. M ansour GM , El-L amie IK, El-Sayed HM , et al. A dnexal mass vascularity assessed by three-dimensional power D oppler: D oes it add to the risk of malignancy index in prediction of ovarian malignancy? Four hundred-case study. Int J Gynecol Cancer 2009; 19:867-72.

61. Cohen LS, Escobar PF, Scharm C, et al. Three-dimensional ultrasound power Doppler improves the diagnostic accuracy for ovarian cancer prediction. Gynecol Oncol 2001;82:40-48.

62. Geomini PM, K luivers K B, M oretE, et al. Evaluation of adnexal masses with three-dimensional ul trasonography. Obstet Gynecol 2006;108:1167-75.

63. Alcázar JL, Castillo G. Comparison of two-dimensional and three-dimensional power Doppler imaging in complex adnexal masses for the prediction of ovarian cancer. A mJ O bstet Gynecol 2005;192:807-12.

64. Alcazar J L, M erce LT, Garcia M anero M. Three-dimensional power D oppler vascular sampling: A new method for predicting ovarian cancer in vascularized complex adnexal masses. J Ultrasound M ed 2005;24:689-96.

65. Testa A C, A jossa S, Ferrandina G, et al. Does quantitative analysis of three-dimensional power D oppler angiography have a role in the diagnosis of malignant pelvic solid tumors? A preliminary study. U Itrasound Obstet Gynecol 2005;26:67-72.
66. Jokubkiene $L$, Sladkevicius $P, V$ alentin $L$. Does threedimensional power Doppler ultrasound help in discrimination between benign and malignant ovarian masses? Ultrasound Obstet Gynecol 2007;29:215-25.

67. K udla MJ, Timor-Tritsch IE, Hope JM, et al. Spherical tissue sampling in three-dimensional power Doppler angiography: A new approach for evaluation of ovarian tumors. J Ultrasound M ed 2008;27:425-33.

68. Ohel I, Sheiner E, A richa-Tamir B, et al. Three-dimensional power Doppler ultrasound in ovarian cancer and its correlation with histology. Arch Gynecol O bstet 2010;281:919-25.

69. A lcázar JL, Prka M. Evaluation of two different methods for vascular sampling by three-dimensional power Doppler angiography in solid and cystic-solid adnexal masses. U Itrasound Obstet Gynecol 2009;33:349-54.

70. K udla M, A Icázar JL. D oes the size of three-dimensional power Doppler spherical sampling affect the interobserver reproducibility of measurements of vascular indices in adnexal masses? U Itrasound O bstet Gynecol 2009;34:732-34.

71. Alcázar J L, Rodriguez D, Royo $P$, et al. Intraobserver and interobserver reproducibility of three-dimensional power Doppler vascular indices in assessment of solid and cystic-solid adnexal masses. J Ultrasound M ed 2008;27:1-6.

72. Geomini PM, Coppus SF, Kluivers KB, et al. Is threedimensional ultrasonography of additional value in the assessment of adnexal masses? Gynecol Oncol 2007;106: 153-59.

73. Alcázar JL, Rodriguez D. Three-dimensional power Doppler vascular sonographic sampling for predicting ovarian cancer in cystic-solid and solid vascularized masses. J Ultrasound Med 2009;28:275-81.

74. Kudla MJ, Alcázar JL. Does sphere volume affect the performance of three-dimensional power Doppler virtual vascular sampling for predicting malignancy in vascularized solid or cystic-solid adnexal masses? U Itrasound O bstet Gynecol 2010;35:602-08.

75. Guerriero S, A jossa S, Piras S, et al. Three-dimensional quantification of tumor vascularity as a tertiary test after B-mode and power Doppler evaluation for detection of ovarian cancer. J Ultrasound M ed 2007;26:1271-78.

76. A lcázar J L. T umor angiogenesis assessed by three-dimensional power Doppler ultrasound in early, advanced and metastatic ovarian cancer: A preliminary study. U Itrasound O bstet G ynecol 2006;28:325-29.

77. Y aman $C$, Fridrik M. Three-dimensional ultrasound to assess the response to treatment in gynecological malignancies. Gynecol Oncol 2005;97:665-68.

78. Su J M, Huang Y F, Chen H HC, Gheng Y M, Chou CY. Threedimensional power Doppler ultrasound is useful to monitor the response to treatment in a patient with primary papillary serous carcinoma of the peritoneum. Ultrasound M ed Biol 2006;32: $623-26$

\section{ABOUT THE AUTHOR}

\section{Juan Luis Alcázar}

Department of Obstetrics and Gynecology, Clinica Universidad de Navarra, U niversity of N avarra, Pamplona, Spain

CorrespondenceAddress A vendidaPio X II, 36 31008, Pamplona, Spain Phone: +349482962354, Fax: +34948296500, e-mail: jlalcazar@unav.es 